\title{
Cabergoline for Cushing's disease: a large retrospective multicenter study
}

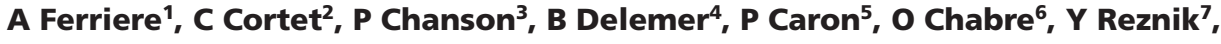 \\ J Bertherat ${ }^{8}$, V Rohmer' ${ }^{9}$ C Briet ${ }^{9}$, I Raingeard ${ }^{10}$, F Castinetti11, A Beckers ${ }^{12}$, \\ L Vroonen ${ }^{12}$, D Maiter ${ }^{13}$, F L Cephise-Velayoudom ${ }^{14}$, M L Nunes ${ }^{1}$, M Haissaguerre1 \\ and A Tabarin ${ }^{1}$ \\ ${ }^{1} \mathrm{CHU}$ Bordeaux, Hôpital Haut-Lévêque, Service d'Endocrinologie, Diabétologie et Nutrition, Pessac, \\ France or INSERM U862, Neurocentre Magendie, Université Bordeaux, Bordeaux Cedex, France, ${ }^{2} \mathrm{CHRU}$ Lille, \\ Service d'Endocrinologie, Diabétologie et Métabolisme, Lille Cedex, France, ${ }^{3}$ Assistance Publique-Hôpitaux de \\ Paris, Hôpitaux universitaires Paris-Sud, Hôpital de Bicêtre, Service d'Endocrinologie et des Maladies de la \\ Reproduction, Le Kremlin Bicêtre, France, ${ }^{4} \mathrm{CHU}$ Reims, Hôpital Robert Debré, Service d'Endocrinologie, \\ Diabétologie et Nutrition, Reims, France, ${ }^{5} \mathrm{CHU}$ Toulouse, Hôpital Larrey, Service d'Endocrinologie, Maladies \\ Métaboliques et Nutrition, Toulouse cedex 9, France, ${ }^{6} \mathrm{CHU}$ Grenoble Alpes, Service d'Endocrinologie-Diabétologie, \\ Boulevard de la Chantourne, La Tronche, France, ${ }^{7} \mathrm{CHU}$ Caen, Service d'Endocrinologie-Diabétologie, \\ CAEN cedex 9, France, ${ }^{8}$ Assistance Publique-Hôpitaux de Paris, Hôpitaux universitaires Paris-Centre, \\ Hôpital Cochin, Service d'Endocrinologie et Maladies Métaboliques, Paris, France, ${ }^{9} \mathrm{CHU}$ Angers, Département \\ d'Endocrinologie-Diabétologie-Nutrition, Angers Cedex 9, France, ${ }^{10} \mathrm{CHU}$ Montpellier, Service d'Endocrinologie, \\ Diabète, Maladies métaboliques, Montpellier, France, ${ }^{11}$ Assistance Publique-Hôpitaux de Marseille, Hôpital de la \\ Conception, Service d'Endocrinologie, Diabètes et Maladies Métaboliques, Marseille, France, ${ }^{12} \mathrm{CHU}$ Liège, \\ Service d'Endocrinologie, Domaine Universitaire du Sart Tilman, Liège, Belgique, ${ }^{13}$ Clinique Universitaire Saint Luc, \\ Service d'Endocrinologie et de Nutrition, Bruxelles, Belgique, and ${ }^{14} \mathrm{CHU}$ Pointe à Pitre, Service d'Endocrinologie, \\ Pointe à Pitre, France
}

Correspondence should be addressed to A Tabarin Email antoine.tabarin@chubordeaux.fr

\begin{abstract}
Objective: The efficacy of cabergoline in Cushing's disease (CD) is controversial. The aim of this study was to assess the efficacy and tolerability of cabergoline in a large contemporary cohort of patients with CD.

Design: We conducted a retrospective multicenter study from thirteen French and Belgian university hospitals. Methods: Sixty-two patients with CD received cabergoline monotherapy or add-on therapy. Symptom score, biological markers of hypercortisolism and adverse effects were recorded.

Results: Twenty-one (40\%) of 53 patients who received cabergoline monotherapy had normal urinary free cortisol (UFC) values within 12 months (complete responders), and five of these patients developed corticotropic insufficiency. The fall in UFC was associated with significant reductions in midnight cortisol and plasma ACTH, and with clinical improvement. Compared to other patients, complete responders had similar median baseline UFC ( 2.0 vs $2.5 x$ ULN) and plasma prolactin concentrations but received lower doses of cabergoline ( $1.5 \mathrm{vs} 3.5 \mathrm{mg} /$ week, $P<0.05)$. During long-term treatment ( $>12$ months), cabergoline was withdrawn in $28 \%$ of complete responders because of treatment escape or intolerance. Overall, sustained control of hypercortisolism was obtained in $23 \%$ of patients for 32.5 months (19-105). Nine patients on steroidogenesis inhibitors received cabergoline add-on therapy for 19 months (1-240). Hypercortisolism was controlled in $56 \%$ of these patients during the first year of treatment with cabergoline at $1.0 \mathrm{mg} /$ week (0.5-3.5).

Conclusions: About $20-25 \%$ of CD patients are good responders to cabergoline therapy allowing long-term control of hypercortisolism at relatively low dosages and with acceptable tolerability. No single parameter, including the baseline UFC and prolactin levels, predicted the response to cabergoline.
\end{abstract}

() 2017 European Society of Endocrinology Printed in Great Britain
Published by Bioscientifica Ltd. 


\section{Introduction}

Cushing's disease (CD) is the most common form of Cushing's syndrome and is responsible for numerous comorbidities and increased mortality (1). The recommended first-line treatment for $\mathrm{CD}$ is transsphenoidal surgery, which induces remission of hypercortisolism in around $70 \%$ of cases. However, CD recurs in $\sim 20 \%$ of patients, and the overall cure rate after surgery is therefore about $50 \%$ (2). A number of second-line treatments, including pituitary irradiation, bilateral adrenalectomy and drugs, can be offered when surgery is ineffective or not feasible (2). Steroidogenesis inhibitors are the most widely used drugs in this setting. From a pathophysiological standpoint, drugs that target the pituitary adenoma to control ACTH secretion and corticotroph tumor growth would be the ideal alternative treatment $(3,4)$.

Cabergoline, a dopamine D2 receptor (D2R) agonist, is widely used in the treatment of prolactinomas. D2R is expressed by a subset of corticotroph adenomas and mediates inhibition of ACTH secretion by dopamine agonists in vitro $(5,6)$. In five clinical studies, cabergoline monotherapy normalized 24-h urinary free cortisol (UFC) in $25-40 \%$ of $C D$ patients $(4,5,7,8,9)$. However, these studies were small (maximum 30 patients; $<20$ patients in $3 / 5$ studies $(5,8,9))$, treatment lasted less than six months in $3 / 5$ studies $(5,8,9)$, important biological endpoints such as midnight cortisol were never mentioned and information on clinical efficacy was lacking in more than half of the studies. The efficacy of cabergoline add-on therapy is also poorly documented. Intriguingly, a recent prospective study failed to show gradual and dose-dependent correction of hypercortisolism at shortterm in $20 \mathrm{CD}$ patients treated with increasing doses of cabergoline $(0.5-5.0 \mathrm{mg} /$ week) (10). The efficacy of cabergoline in $\mathrm{CD}$ is therefore debatable (Table 1).

To improve our knowledge of the efficacy and tolerability of cabergoline in $\mathrm{CD}$ patients treated in routine clinical practice, either alone or in combination with steroidogenesis inhibitors, we conducted a large retrospective study.

\section{Patients and methods}

An extensive search for CD patients treated with cabergoline was conducted in 13 university hospitals located in France or French-speaking Belgium. Data on 62 CD patients treated with cabergoline between 2003 and 2015 were included in this retrospective analysis, with the following inclusion criteria: (i) active clinical Cushing's disease associated with increased UFC at cabergoline introduction; (ii) the following evidence of CD: identification of an ACTH-immunostaining pituitary adenoma at histological analysis after surgery, or an unequivocal ACTH gradient during IPSS, or an unequivocal pituitary tumor on magnetic resonance

Table 1 Review of literature.

\begin{tabular}{|c|c|c|c|c|c|c|}
\hline Study & Design & $n$ & Dose (mg/week) & Response criteria & $\begin{array}{l}\text { Patients with controlled } \\
\text { hypercortisolism }(\%)\end{array}$ & $\begin{array}{l}\text { Maximal duration } \\
\text { of treatment }\end{array}$ \\
\hline$\overline{\text { Pivonello (2004) (4) }}$ & $\begin{array}{l}\text { Retrospective, } \\
\text { multicenter, } \\
\text { monotherapy }\end{array}$ & $\overline{10}$ & $2.2(1.0-3.0)$ & UFC & 40 & 3 months \\
\hline Pivonello (2009) (6) & $\begin{array}{l}\text { Prospective, } \\
\text { multicenter, } \\
\text { monotherapy }\end{array}$ & 20 & $3.5(1.0-7.0)$ & UFC & $\begin{array}{l}35 \text { (short term) } \\
40 \text { (long term) }\end{array}$ & 2 years \\
\hline Lila (2010) (17) & $\begin{array}{l}\text { Prospective, } \\
\text { multicenter, } \\
\text { monotherapy }\end{array}$ & 20 & $3.6(1.0-5.0)$ & $\begin{array}{l}\text { Midnight cortisol } \\
\text { and/or LDDST }\end{array}$ & 28 & 12 months \\
\hline Godbout (2010) (7) & $\begin{array}{l}\text { Retrospective, } \\
\text { multicenter, } \\
\text { monotherapy }\end{array}$ & 30 & $2.1(0.5-4.0)$ & UFC & $\begin{array}{l}37 \text { (short term) } \\
30 \text { (long term) }\end{array}$ & 3 years \\
\hline Vilar (2010) (8) & $\begin{array}{l}\text { Prospective, } \\
\text { monocenter, } \\
\text { bitherapy }\end{array}$ & 12 & $2.5(1.0-3.0)$ & UFC & 25 & 6 months \\
\hline Barbot (2014) (9) & $\begin{array}{l}\text { Prospective, } \\
\text { monocenter, } \\
\text { bitherapy }\end{array}$ & 14 & $2.3(0.5-3.0)$ & UFC & $\begin{array}{l}33 \text { (short term, monotherapy) } \\
100 \text { (long term, bitherapy) }\end{array}$ & 12 months \\
\hline Burman (2016) (10) & $\begin{array}{l}\text { Prospective, } \\
\text { monocenter, } \\
\text { monotherapy }\end{array}$ & 20 & $4.7(2.5-5.0)$ & UFC & 0 & 6 weeks \\
\hline
\end{tabular}

$n$, number of patients; UFC, urinary free cortisol; LDDST, low-dose dexamethasone suppression test. 
imaging (MRI), associated with a positive response to both CRH and high-dose dexamethasone; and (iii) at least one month of cabergoline administration, either alone or as add-on therapy. Patients treated concomitantly with mitotane were excluded.

Previous treatments for CD were recorded, along with the results of clinical, biological and MRI investigations performed before cabergoline introduction and at the last evaluation during treatment.

To evaluate retrospectively the clinical intensity of Cushing's syndrome from medical charts, we developed a clinical score. An arbitrary score of 1 was recorded in the presence of virilism, buffalo hump and obesity. A score of 2 was recorded in the presence of specific or more severe symptoms such as hypokalemia, purple striae, proximal muscle weakness and fragile skin. A score of 1 was recorded for glucose intolerance and a score of 2 for diabetes. Scores of 1 and 2 were recorded for hypertension of grade 1-2 and grade 3 respectively. In the presence of psychiatric disorders, a score of 1 was recorded for sleeping/cognitive disturbances and a score of 2 for severe psychiatric disorders. The maximum score was 17. As some information was missing in medical records, the score of each patient was reported to its theoretical maximum value (Supplementary Table 1, see section on supplementary data given at the end of this article).

An improvement in body weight was defined as a loss of $\geq 5 \%(11,12)$. An improvement in arterial pressure was defined as a decline in the grade of hypertension (13), and/or a $\geq 25 \%$ reduction in the daily doses of hypotensive drug $(14,15)$. An improvement in glycemic control was defined as a decrease of $\geq 0.5 \%$ in the Hba1c, with no change in antidiabetic treatment, and/or a $\geq 25 \%$ reduction in the daily doses of antidiabetic drug $(14,15)$.

Biological investigations included UFC, 0800-h plasma ACTH, midnight plasma cortisol, the mean of three to six plasma cortisol values (cortisol day curve or CDC) and plasma prolactin and were performed during hospitalization. The cabergoline treatment duration, dosage and tolerability were also recorded.

Adverse effects were classified using the Common Terminology Criteria for Adverse Events (CTCAEv4.02).

The first evaluation after cabergoline prescription was performed within 1 month, 3 months and 6 months in 40, 75 and $100 \%$ of patients (median: 2.0 months, range: 0.5-6.0). Once UFC was controlled, UFC was collected with a median frequency of 3.0 months (range: 1.0-6.0). If necessary, the cabergoline dosage was increased by 0.5 to $1.5 \mathrm{mg} /$ week, depending on the investigator's judgment, until the UFC normalized.
Patients whose UFC normalized on two consecutive occasions or who developed corticotropic insufficiency during treatment were considered to be complete responders. Patients who achieved a $\geq 50 \%$ decrease in UFC on two consecutive occasions, without normalization, were considered to be partial responders. An increase in UFC above the normal range during follow-up of complete responders was considered to represent treatment escape. Corticotropic insufficiency was defined by a 0800-h plasma cortisol $<140 \mathrm{nmol} / \mathrm{L}$ and/or a cortisol peak below $500 \mathrm{nmol} / \mathrm{L}$ after the short synacthen test.

ACTH and plasma and urinary cortisol were measured by the endocrine reference laboratory in each center, using a variety of assays during the study period, and values were analyzed by comparison with normal ranges used in each assay (Supplementary Tables 2, 3 and 4).

The data were collected under conditions of regular clinical care. Local ethics committee approval was obtained for the use of the data.

GraphPad Prism, version 6.01-2012 was used for statistical analysis. Most of quantitative data were not normally distributed, and all results are presented as median and range. Median UFC was normalized to the upper normal limit (ULN) of the relevant assay. Quantitative data were compared using Student's $t$ test, ANOVA, or the Mann-Whitney, Kruskal-Wallis or Wilcoxon test as appropriate. Qualitative data were analyzed with the $\chi^{2}$ test or Fisher's exact test as appropriate. Correlation studies were performed using Spearman's test. Statistical significance was set at $P<0.05$.

\section{Results}

The main characteristics of the 62 patients are listed in Table 2.

At baseline, patients had at least one increased UFC and $62 \%$ of these had increased UFC in two separate samples. UFC was 1.1-2.×ULN, 2.1-4.0×ULN and $>4.0 \times \mathrm{ULN}$ in $48 \%, 32 \%$ and $19 \%$ of patients respectively.

\section{Cabergoline monotherapy}

Fifty-three patients received cabergoline monotherapy. Nine of these patients received cabergoline as first-line therapy, in preparation for pituitary surgery in four cases. Forty-four patients (83\%) had persistent or recurrent CD after pituitary surgery. Fifteen patients received conventional $(n=5)$ or stereotactic $(n=10)$ radiotherapy prior to cabergoline treatment. The median interval 
Table 2 Main characteristics of the study population.

\begin{tabular}{l} 
Characteristic \\
\hline Age at diagnosis (years) \\
Sex ratio (female/male) \\
Time since diagnosis (years) \\
MRI at diagnosis \\
Microadenoma \\
Macroadenoma \\
No visible lesion \\
Prior pituitary surgery \\
Prior pituitary radiotherapy \\
Comorbidities \\
Overweight/obesity \\
Hypertension \\
Diabetes \\
Hypokalemia \\
Baseline laboratory values \\
UFC ( $\times$ ULN) \\
Midnight plasma cortisol (nmol/L) \\
CDC (nmol/L) \\
0800h ACTH (pmol/L) \\
Plasma prolactin (ng/mL) \\
Prolactin $>20$ ng/mL
\end{tabular}

\begin{tabular}{|c|c|}
\hline Value & $n$ \\
\hline $37.5(7.0-78.0)$ & - \\
\hline $50 / 12$ & - \\
\hline $7.0(0-30.0)$ & - \\
\hline & - \\
\hline $\begin{array}{l}48 \% \\
32 \%\end{array}$ & \\
\hline $20 \%$ & \\
\hline $84 \%$ & - \\
\hline $26 \%$ & - \\
\hline $70 \%$ & 56 \\
\hline $60 \%$ & 58 \\
\hline $38 \%$ & 60 \\
\hline $7 \%$ & 60 \\
\hline $2.1(1.2-29.4)$ & 62 \\
\hline $372.9(52-803)$ & 41 \\
\hline 471.8 (173-969) & 54 \\
\hline $13.7(2.9-40.0)$ & 46 \\
\hline $13.0(1.3-57.4)$ & 30 \\
\hline $27 \%$ & 30 \\
\hline
\end{tabular}

$n$, number of patients with available data; UFC, urinary free cortisol; ULN, upper limit of normal; CDC, cortisol day curve.

between radiotherapy and cabergoline prescription was 2.0 years (range: $0.5-16$ years). Eleven patients had previously received steroidogenesis inhibitors that had been withdrawn because of intolerance.

Cabergoline was introduced at various dosages (1.0 mg/week; range: 0.5-6.0). The weekly maintenance dose of cabergoline was $2.3 \mathrm{mg}$ (range: 0.5-6.0) overall, and $<2,2-3.5$ and $\geq 3.5 \mathrm{mg}$ in respectively $41 \%, 20 \%$ and $39 \%$ patients. Only two (4\%) of the 53 patients received more than $4.0 \mathrm{mg} /$ week. The median treatment duration was seven months (range: 1-105). Eighteen patients (34\%) were treated for less than six months, 16 (30\%) for between six and 12 months and 19 (36\%) for more than 12 months.

During the first year, normal UFC values in at least two consecutive samples were obtained in 21 patients (40\%), of whom five (9\% of the whole cohort) developed corticotropic insufficiency. Corticotropic insufficiency was diagnosed in 5 patients in front of typical clinical symptoms (asthenia and dizziness), low 0800-h plasma cortisol concentrations $(36,99,108,135$ and $179 \mathrm{nmol} / \mathrm{L}$ ) and/or associated with low cortisol peak values following the short synacthen test. Corticotropic insufficiency occurred after three to 105 months of cabergoline exposure at doses ranging from 1.0 to $3.5 \mathrm{mg} /$ week. None of these patients had previously received pituitary radiotherapy. Four of the five patients received hydrocortisone replacement therapy, and cabergoline was withdrawn in the fifth patient. Four patients (7\%) were partial responders, whereas 28 patients (53\%) had unchanged or increased UFC values (Fig. 1). Importantly, baseline UFC was similar in these three response groups (Table 3). In the complete responders, UFC normalized within three months in $52 \%$ of cases and within six

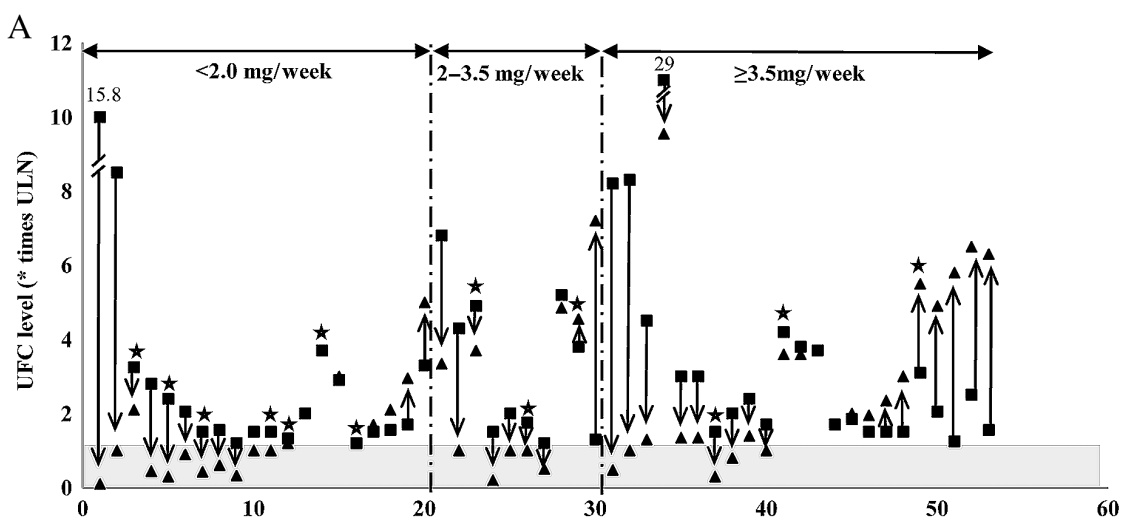

B

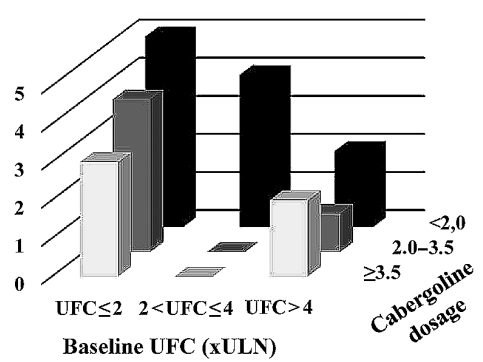

C

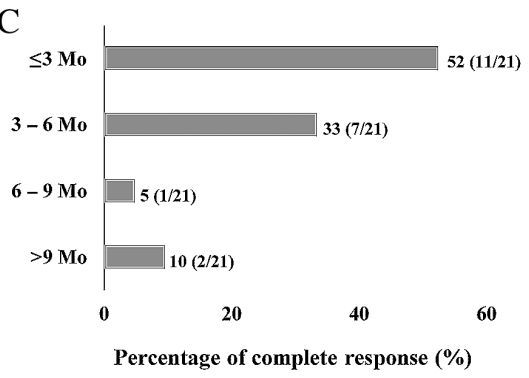

Figure 1

Mains results of cabergoline monotherapy. (A) Changes in urinary free cortisol concentrations before (square) and after (triangle) cabergoline treatment. Stars indicate patients having received pituitary radiotherapy. The gray area indicates the upper limit of normal UFC. Patients are classified according to the cabergoline dosage. (B) Number of complete responders, according to baseline UFC and cabergoline dosage. (C) Time to response in complete responders. UFC, urinary free cortisol; ULN, upper limit of normal; Mo, months. 
Table 3 Main characteristics of complete responders and other patients receiving cabergoline monotherapy.

\begin{tabular}{|c|c|c|c|}
\hline & Responders $(n=21)$ & Other patients $(n=32)$ & $\boldsymbol{P}$ \\
\hline Age at diagnosis & $45.0(11-78)$ & $32.5(7-59)$ & $<0.05$ \\
\hline Sex ratio (female/male) & $18 / 3$ & $28 / 4$ & 1.00 \\
\hline Previous surgery & $18(86 \%)$ & $26(81 \%)$ & 1.00 \\
\hline Previous radiotherapy & $7(33 \%)$ & $6(19 \%)$ & 0.33 \\
\hline \multicolumn{4}{|l|}{ Baseline MRI } \\
\hline Microadenoma & $10(50 \%)$ & $13(42 \%)$ & \\
\hline Macroadenoma & $6(30 \%)$ & $11(35 \%)$ & 0.85 \\
\hline No visible lesion & $4(20 \%)$ & $7(23 \%)$ & \\
\hline Baseline plasma prolactin $(\mathrm{ng} / \mathrm{mL})$ & $14.0(0-43.0) ; n=15$ & $13.1(5-57) ; n=19$ & 0.54 \\
\hline Prolactin $\geq 20 \mathrm{ng} / \mathrm{mL}$ & $n=3$ & $n=6$ & \\
\hline Baseline UFC (xULN) & $2.0(1.2-15.8)$ & $2.5(1.2-29.4)$ & 0.64 \\
\hline Cabergoline dosage (mg/week) & $1.5(0.5-4.0)$ & $3.5(0.5-6.0)$ & $<0.05$ \\
\hline Duration of treatment (month) & $28(3-105)$ & $4(1-48)$ & $<0.001$ \\
\hline
\end{tabular}

n, number of patients with available data; UFC, 24-h urinary free cortisol; ULN, upper limit of normal.

months in $86 \%$ of cases. UFC normalized after 12 months in two patients who received low starting doses and a slow dose escalation (Fig. 1).

The cabergoline dosage associated with UFC normalization in complete responders was $1.5 \mathrm{mg} /$ week (range: $0.5-4.0$ ) overall, and $<2,2-3.5$ and $\geq 3.5 \mathrm{mg}$ in respectively $52 \%, 24 \%$ and $24 \%$ of patients. The maximal dosage used was $4.0 \mathrm{mg} /$ week, in one patient. Interestingly, complete responders received lower doses than other patients at the time cabergoline was discontinued $(1.5 \mathrm{mg} /$ week (range: $0.5-4.0$ ) vs $3.5 \mathrm{mg} /$ week (range: 0.5-6.0), $P<0.05)$. No correlation was found between the decrease in UFC and the cabergoline dosage $(r=-0.25, P=0.10)$. Among complete responders, the cabergoline dosage associated with UFC control did not differ according to baseline hypercortisolism (mild, moderate or severe, as defined previously; $P=0.08$ ) (Fig. 1).

Only age at diagnosis differed between complete responders and the other patients (Table 3). Importantly, baseline prolactin levels were similar.

No significant difference in the prevalence of control of hypercortisolism was found between patients with microadenomas and those with macroadenomas. However, it should be mentioned that four responders $(67 \%)$ were identified among the six patients with a macroadenoma $\geq 20 \mathrm{~mm}$ in size before surgery. This finding is reminiscent of several case reports acknowledging significant shrinkage of corticotropic macroadenomas with dopamine agonists (16-19).

In complete responders, UFC normalization was associated with a $43 \pm 12 \%$ decrease in midnight plasma cortisol (from 331 (range: 250-591) to $180 \mathrm{nmol} / \mathrm{L}$ (range: $80-310), P<0.01$ ), and nadir values were below the $200 \mathrm{nmol} / \mathrm{L}$ threshold in $50 \%$ of patients (20). UFC normalization was also associated with a $54 \pm 9 \%$ decrease in CDCs (from 427 (range: $289-795$ ) to $172 \mathrm{nmol} / \mathrm{L}$ (range: 113-374), $P<0.05)$, and a $48 \pm 4 \%$ decrease in $0800-\mathrm{h}$ ACTH (from 12.0 (range: 7.7-26.2) to $6.1 \mathrm{pmol} / \mathrm{L}$ (range: $3.5-12.0), P<0.05)$. The decrease in UFC correlated with the decrease in $0800 \mathrm{~h}$ plasma ACTH $(r=0.44, P<0.05)$.

The clinical score improved from 31.6 (range: $0-80$ ) to 20.0 (range: $0-40)$ in complete responders $(P<0.05)$, whereas it was unchanged in the other patients $(27.2$ (range: 0-74) vs 29.6 (range: 0-61); $P=0.51$ ). Specifically, body weight, glycemic control and hypertension improved in respectively $25 \%, 40 \%$ and $33 \%$ of complete responders. Hypertension did not improve in patients who were not complete responders.

Eighteen complete responders were treated for more than one year. During long-term follow-up of these patients, a treatment escape occurred in seven patients (39\%) after a median treatment duration of 26 months (range: $6-105$ months). The increase in UFC was $1.7 \times$ ULN (range: 1.1-2.9) (Fig. 2). An increase in the cabergoline dosage (from 0.5 to $1.0 \mathrm{mg} /$ week and from 1.0 to $2.0 \mathrm{mg} /$ week) yielded secondary normalization of UFC in three patients, whereas treatment was withdrawn in four patients treated with 1.5 to $4.0 \mathrm{mg} /$ week. Treatment was also suspended in a complete responder after diagnosis of grade 2 aortic insufficiency but in whom baseline echocardiography had not been performed prior to cabergoline therapy.

Overall, sustained UFC normalization was obtained for 32.5 months (range: $19-105)$ in 12 patients (23\% of the whole cohort and $67 \%$ of complete responders treated for more than a year), at a cabergoline dosage of $1.5 \mathrm{mg} /$ week (range: 0.5-3.5). A sustained improvement in a clinical score was observed during long-term treatment (baseline vs last visit $=25.1$ (range: $0-60$ ) vs 20.0 (range: 5-33)). 
A

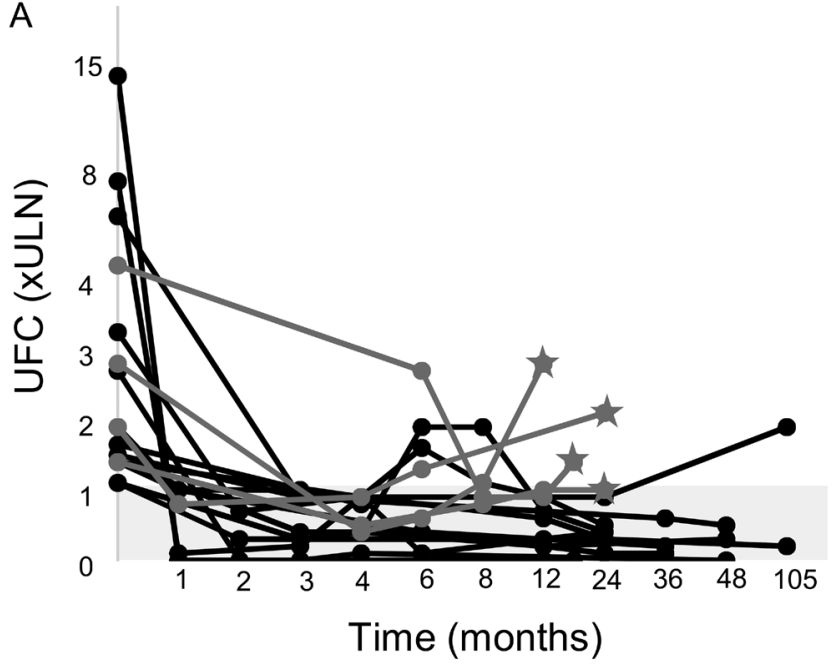

B

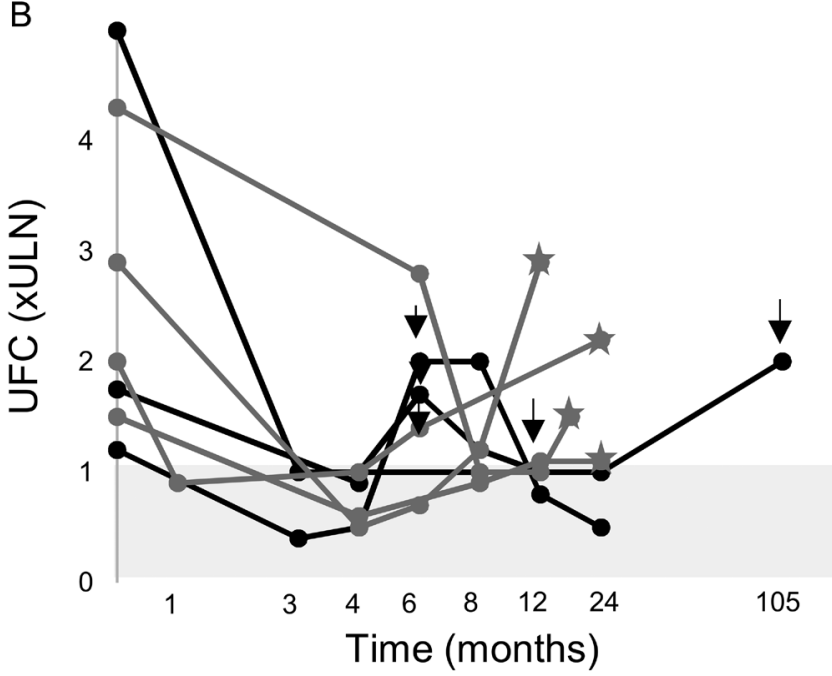

Figure 2

Long-term response to cabergoline monotherapy. (A) Urinary cortisol level during the long term follow-up in eighteen complete responders treated $\geq 1$ year. (B) Focus on the seven patients with treatment escape. Long term complete responders are shown with black lines. Patients who stopped cabergoline because of treatment escape are shown with grey lines. Arrow indicates the increase in cabergoline dosage. The grey area indicates the upper limit of normal of UFC. UFC, urinary free cortisol; ULN, upper limit of normal.

\section{Cabergoline add-on therapy}

Nine patients received cabergoline add-on during ongoing treatment with steroidogenesis inhibitors, either in preparation for pituitary surgery (one patient) or after unsuccessful surgery (eight patients). Seven of these nine patients were treated with 600 to $1200 \mathrm{mg}$ /day ketoconazole and two were treated with 3750 to $6000 \mathrm{mg} /$ day metyrapone, for $18.1 \pm 8.2$ months. Two patients had received pituitary radiotherapy, less than one year previously.

The maximal weekly dose of cabergoline was $1.0 \mathrm{mg} /$ week overall (range: $0.5-3.5$ ), $<2.0 \mathrm{mg}$ in eight patients and $3.5 \mathrm{mg}$ in one patient. The median duration of cabergoline combination therapy was 19 months (range: 1-240). Two of the nine patients were treated for less than five months, one patient was treated for six months and six patients were treated for more than 12 months.

During the first year, five patients (56\%) were complete responders and four patients were non-responders (Fig. 3). Baseline UFC was similar in the responders and non-responders (1.8 (range: $1.2-4.0)$ vs $3.2 \times \mathrm{ULN}$ (range: $1.6-5.6), P=0.29)$. UFC normalized within six months in two patients, and within eight months in three patients.

Responders and non-responders received a similar cabergoline dosage $(1.0 \mathrm{mg} /$ week (range: $0.5-3.5)$ and $1.0 \mathrm{mg} /$ week (range: $0.5-1.5$ ), respectively; $P=0.59$ ).

In complete responders, UFC normalization was associated with a $57 \pm 26 \%$ decrease in midnight cortisol (541 (range: $373-709$ ) to $278 \mathrm{nmol} / \mathrm{L}$ (range: 66-489); $P=0.67$ ), a $47 \pm 18 \%$ decrease in CDC (551 (range: 467 635 ) to $308 \mathrm{nmol} / \mathrm{L}$ (range: $164-452$ ), $P=0.33$ ), and a $38 \pm 32 \%$ decrease in $0800 \mathrm{~h}$ plasma ACTH (23.3 (range: $21.5-25.0$ ) to $14.0 \mathrm{pmol} / \mathrm{L}$ (range: 7.7-20.2), $P=0.33$ ).

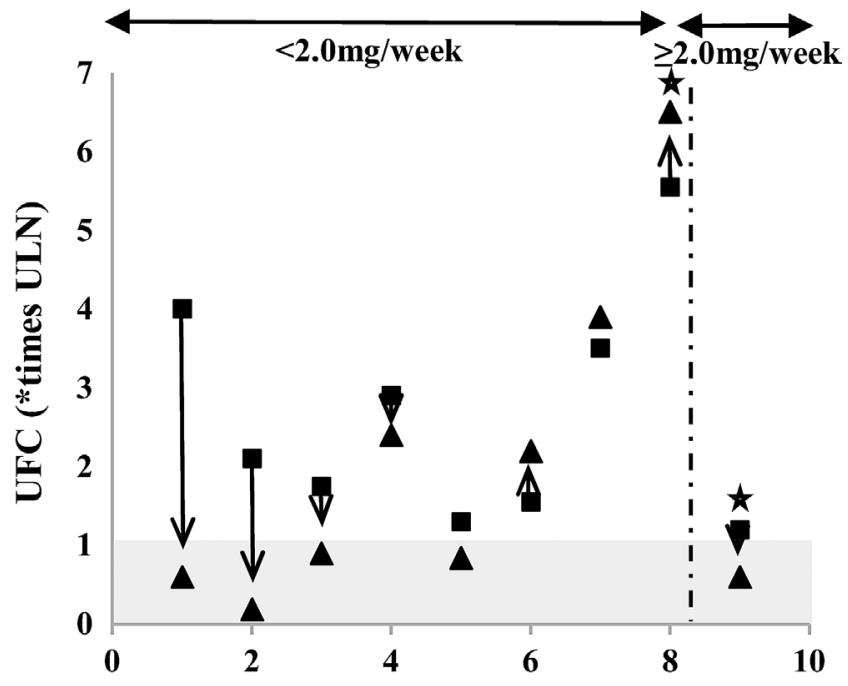

Figure 3

Changes in urinary free cortisol concentrations before (square) and after (triangle) cabergoline add-on therapy. Stars indicate patients having received pituitary radiotherapy. The gray area indicates the upper limit of normal UFC. Patients are classified according to the cabergoline dosage. UFC, urinary free cortisol; ULN, upper limit of normal. 
The clinical score improved by 10 points in complete responders, whereas it worsened by 6.4 points in nonresponders $(P<0.05)$. More specifically, body weight, glycemic control and hypertension improved in respectively $40 \%, 67 \%$ and $50 \%$ of complete responders.

Four complete responders to cabergoline add-on therapy were treated for more than one year. A treatment escape occurred in two of these patients, after 12.5 months of treatment (range: 6-19). The increase in UFC was 1.5 and $1.4 \times$ ULN. This led to cabergoline withdrawal in one case, while pasireotide add-on induced UFC normalization in the other patient. Treatment was withdrawn for intolerability after 19 months in one patient. Overall, sustained UFC normalization was achieved for 130 months (range: 20-240) in two patients ( $22 \%$ of the add-on subgroup) at a cabergoline dosage of $1.0 \mathrm{mg} /$ week.

\section{Cabergoline tolerability}

Safety data were available for 57 patients.

Adverse events occurred in 17 patients (29\%): dizziness (14\%), nausea (12\%), asthenia (12\%), dyspepsia (3\%), abdominal pain, hypotension, muscle pain, alopecia and edema ( $2 \%$ each). Adverse events were mostly mild (grade 1 or 2). Eight patients (13\%) stopped taking cabergoline because of poor tolerance. A grade 4 maniac episode occurred during cabergoline add-on therapy (with ketoconazole) in a patient with a history of depression. The maniac episode subsided after cabergoline withdrawal.

\section{Discussion}

This is the largest cohort study of cabergoline therapy in Cushing's disease $(4,5,7,8,9,10,21,22)$. Interestingly, we identified only 53 cases of cabergoline monotherapy in our nationwide survey spanning a 12-year period, whereas Castinetti et al., using a similar approach, identified more than 200 patients treated with ketoconazole during a 17-year period (23). This suggests that cabergoline has not gained wide acceptance in the treatment of CD.

Our results for cabergoline monotherapy support the efficacy observed in the largest previous series (involving 20 and 30 patients), which showed UFC control in 35\% to $37 \%$ of patients in the short term, and in $30 \%$ to $40 \%$ of patients treated for more than 12 months $(4,7)$.

The relatively modest response rate observed here is not surprising, in view of the low prevalence of high
D2R expression by corticotroph adenomas (5), but it may also be related to the relatively low cabergoline dosage (2.0 mg/week (range: 0.5-6.0)), as most prospective series used maximal median doses of 3.5 and $3.6 \mathrm{mg} /$ week $(7,21)$. Under-titration occurs frequently in real-life endocrinological treatment of pituitary diseases $(23,24,25$, 26). However, we observed no simple correlation between the cabergoline dosage and the decrease in UFC. Thirtyone patients received at least $2 \mathrm{mg}$ /week of cabergoline in monotherapy. Ten of these patients (32\%) were complete responders, four (13\%) were partial responders and 17 (55\%) were non-responders. Interestingly, our results show that a subset of $\mathrm{CD}$ patients is very responsive to $\mathrm{D} 2 \mathrm{R}$ agonists and ideal candidates for cabergoline treatment. For example, hypercortisolism was controlled for 6 and 48 months in two patients of our series with only $0.5 \mathrm{mg} /$ week of cabergoline. Such remarkably responsive cases have also been reported by Pivonello et al. (7) and Godbout et al. (4). In this perspective, we also report for the first time that corticotropic insufficiency can occur on cabergoline, a phenomenon that may be interpreted as a desirable side effect. Similarly, the probability of controlling hypercortisolism did not correlate with the baseline UFC. More than $67 \%$ of complete responders in whom the baseline UFC was above $2 x U L N$ received less than $2.0 \mathrm{mg} /$ week. No single criterion predicted individual response to cabergoline, and the controversial prognostic value of an elevated prolactin concentration $(4,7)$ was not confirmed here. From a practical perspective, our findings imply that the severity of hypercortisolism should not be a criterion for deciding whether to proceed or not with cabergoline treatment, a concept that is discrepant with the use of cabergoline as an adjunctive treatment for acromegaly associated with mild increase in $\operatorname{IGF}-1(27,28)$ or with the use of pasireotide in CD (29). Our results also emphasize the need for regular monitoring of morning plasma cortisol, a poor marker of hypercortisolism, to detect corticotropic insufficiency in controlled patients, including those treated with low doses of cabergoline and because both cabergoline and corticotropic insufficiency can cause asthenia, dizziness and hypotension. Prospective studies are needed to study the possible correlation between cabergoline efficacy and the intensity of D2R expression in corticotropic adenomas. This would represent a first step towards individualized medication in this difficult situation.

Our study also provides further insights into the biochemical effects of cabergoline. Although UFC normalization is a relevant therapeutic endpoint, some patients have true hypercortisolism and active disease 
despite normal UFC (29, 30, 31), and lowering the midnight cortisol might be an important goal $(32,33,34)$. Although we were unable to study the precise circadian rhythm of plasma cortisol, it is worth mentioning that a $43 \%$ decrease in midnight plasma cortisol occurred in complete responders, and that $50 \%$ of these patients had nadir values below $200 \mathrm{nmol} / \mathrm{L}$. Elsewhere, the average $48 \%$ decrease in plasma ACTH in complete responders is consistent with a primary drug action on the corticotrophic adenoma $(5,6)$.

More data are needed on the clinical impact of cabergoline in CD, especially during long-term treatment. In keeping with our biological findings, UFC normalization was associated with a significant improvement in a clinical score and with sustained regression of cortisol-associated comorbidities during long-term treatment. Contrary to a previous report $(7,35)$, we observed no improvement in blood pressure in uncontrolled patients; this argues against a beneficial vasodilatory action of cabergoline at the doses used here.

Two specific observations in patients who received cabergoline monotherapy merit discussion. First, the time taken to control UFC was highly variable ( $<3$ months in $52 \%$ of patients, $<6$ months in $86 \%$ ). Pivonello and Godbout reported a lag time of three months in their series $(4,7)$. However, prompt control of hypercortisolism is recommended to limit exposure to excess cortisol (36). In contrast, dopamine agonists work quickly in patients with prolactinomas. This slow action of cabergoline would explain the poor results obtained in the short-term prospective study by Burman et al. (10), which evaluated the efficacy of increasing cabergoline doses during a period of only six weeks. Elsewhere, the low starting dosage of cabergoline used in our study and in most other published studies, together with the variable timing and intensity of dose increments across the participating centers, prevented us from precisely estimating the time to maximal response. Second, a treatment escape occurred in 39\% of complete responders during long-term treatment. This was the case of $19 \%$ of 21 patients treated for more than 12 months in others studies $(4,7)$. Intriguingly, this was observed in a patient who previously experienced corticotropic insufficiency. The mechanisms responsible for escape to cabergoline treatment are unknown. It may involve receptors downregulation, various post-receptor desensitization mechanisms or selection of adenomatous cells that are less sensitive to D2R agonists. Elsewhere, the possibility of transient fluctuations or poor treatment adherence cannot be excluded. In practical terms, these observations suggest that repeated clinical and biological evaluation must continue throughout treatment, even when prolonged eucortisolism is obtained. Normal UFC values may be re-established by increasing the cabergoline dosage.

The results of cabergoline add-on during ongoing steroidogenesis inhibition have so far been reported in only 23 patients $(8,9)$, who were treated for no more than 12 months. Despite the low cabergoline doses used in our study $(1.0 \mathrm{mg} /$ week (range: $0.5-3.5)$ ), the rate of hypercortisolism control during the first year of treatment compares well with that previously published (63\% to $71 \%$ of patients controlled on $2.4 \mathrm{mg} /$ week) $(8,9)$. Although very few of our patients received longterm cabergoline add-on therapy, we obtained evidence that efficacy tends to wane, due both to a treatment escape and to late adverse effects. Cabergoline has been reported to help control hypercortisolism when combined with pasireotide and ketoconazole (22).

As previously reported, cabergoline was well tolerated. The withdrawal rate was low, and only one severe psychiatric episode that resolved after drug withdrawal was reported.

The limitations of our study are mostly related to its retrospective design including selection bias and to the lack of a standardized dose escalation plan and monitoring protocol. Within- and between-laboratories variability over time in the methods of cortisol measurement and reference ranges may have induced some random bias in the calculation of CDC and midnight plasma cortisol during the follow-up. In addition, large variations in UFC are common in CD patients (37). Therefore, the differentiation between a definitive control of hypercortisolism secondary to cabergoline treatment and spontaneous normalization of UFC may be difficult in patients with mild hypercortisolism and long intervals between evaluations. Another limitation of our study was the identification of 'true' treatment escapes. Indeed, cabergoline was stopped or increased in dosage when UFC was increased in a single 24-h urine collection. Moreover, the increase in UFC was sometimes minimal $(\leq 1.5 \times$ ULN in two of the seven patients). It is therefore tempting to speculate that some of these episodes were transient, marginal fluctuations in UFC (37) and that the rate of treatment escape in our study is overestimated. Our assessment of efficacy was hampered by the difficulty of quantifying clinical manifestations from the medical records, and it should be noted that our arbitrary symptom score has not been validated. A standardized tool for evaluating and quantifying clinical manifestations of 
Cushing's syndrome is an unmet need. Eight of the 26 complete responders to cabergoline in our study had previously received pituitary radiotherapy, 0.5 to 16 years before cabergoline initiation. Although we cannot exclude a role of pituitary irradiation in the control of hypercortisolism $(2,31,38)$, it is noteworthy that none of the patients who developed corticotropic insufficiency on cabergoline had received radiotherapy. Moreover, the rate of UFC normalization in patients who did not receive radiotherapy within three years before treatment $(n=46)$ is $33 \%$ for cabergoline monotherapy and $57 \%$ for cabergoline add-on therapy. These results are roughly similar to that observed in the whole cohort suggesting that radiotherapy is unlikely to be a confounding factor in this series.

In conclusion, this study conducted in tertiary health care centers suggests that cabergoline provides much the same degree of control of hypercortisolism in Cushing's syndrome as that reported with pituitarydirected medications such as pasireotide (29). Although the efficacy of cabergoline and the time taken to reduce cortisol secretion are less favorable than reported with steroidogenesis inhibitors $(23,24,39)$, its simplicity of use, safety profile and relatively low cost make cabergoline a useful drug for a subset of patients who are very responsive to $\mathrm{D} 2 \mathrm{R}$ agonists. Unfortunately, there is no simple way of identifying these patients. Some data suggest that the length of exposure to hypercortisolism is somehow related to the persistence of comorbidities and reduced life expectancy in patients cured of Cushing's disease $(2,40)$. As most of candidates to cabergoline treatment have experienced surgical failure, we anticipate that they may have been exposed to long periods of hypercortisolism and believe that UFC control should be obtain as soon as possible. Complementary studies evaluating precisely the delay in obtaining normalization of UFC in responsive patients are urgently needed (4, $7,10)$. In the meantime, we suggest a starting dose of 1.5 to $2.0 \mathrm{mg} /$ week, corresponding to the average dose received by our complete responders and that is usually well tolerated $(27,37)$. We recommend measuring UFC every 2-4 weeks together with $0800 \mathrm{~h}$ plasma cortisol during titration and increase cabergoline dosage if UFC is still increased. According to our data and those from the literature, there is probably few chances to control the disease if no significant decrease in UFC is observed after 1-2 months of treatment at $4 \mathrm{mg} /$ week (38). We also recommend regular evaluation of morning plasma cortisol to screen for corticotropic insufficiency that may be missed by measuring only UFC. Finally, it is important to watch for signs of therapeutic escape, even in patients with good long-term control.

\section{Supplementary data}

This is linked to the online version of the paper at http://dx.doi.org/10.1530/ EJE-16-0662.

\section{Declaration of interest}

The authors declare that there is no conflict of interest that could be perceived as prejudicing the impartiality of the research reported.

\section{Funding}

This research did not receive any specific grant from any funding agency in the public, commercial or not-for-profit sector.

\section{References}

1 Dekkers OM, Horváth-Puhó E, Jørgensen JOL, Cannegieter SC, Ehrenstein V, Vandenbroucke JP, Pereira AM \& Sorensen HT. Multisystem mor bidity and mortality in Cushing's syndrome: a cohort study. Journal of Clinical Endocrinology and Metabolism 201398 2277-2284. (doi:10.1210/jc.2012-3582)

2 Nieman LK, Biller BMK, Findling JW, Murad MH, Newell-Price J, Savage MO, Tabarin A \& Endocrine Society. Treatment of Cushing's syndrome: an endocrine society clinical practice guideline. Journal of Clinical Endocrinology and Metabolism 2015100 2807-2831. (doi:10.1210/jc.2015-1818)

3 Bertagna X \& Guignat L. Approach to the Cushing's disease patient with persistent/recurrent hypercortisolism after pituitary surgery. Journal of Clinical Endocrinology and Metabolism. 201398 1307-1318. (doi:10.1210/jc.2012-3200)

4 Godbout A, Manavela M, Danilowicz K, Beauregard H, Bruno OD \& Lacroix A. Cabergoline monotherapy in the long-term treatment of Cushing's disease. European Journal of Endocrinology 2010163 709-716. (doi:10.1530/EJE-10-0382)

5 Pivonello R, Ferone D, De Herder WW, Kros JM, De Caro MLDB, Arvigo M, Annunziato L, Lombardi G, Colao A, Hofland LJ et al. Dopamine receptor expression and function in corticotroph pituitary tumors. Journal of Clinical Endocrinology and Metabolism 200489 2452-2462. (doi:10.1210/jc.2003-030837)

6 Van der Pas R, Feelders RA, Gatto F, de Bruin C, Pereira AM, van Koetsveld PM, Sprij-Mooij DM, Waaijers AM, Dogan F, Schulz S et al. Preoperative normalization of cortisol levels in Cushing's disease after medical treatment: consequences for somatostatin and dopamine receptor subtype expression and in vitro response to somatostatin analogs and dopamine agonists. Journal of Clinical Endocrinology and Metabolism 201398 1880-1890. (doi:10.1210/jc.2013-1987)

7 Pivonello R, De Martino MC, Cappabianca P, De Leo M, Faggiano A, Lombardi G, Hofland LJ, Lamberts SWJ \& Colao A. The medical treatment of Cushing's disease: effectiveness of chronic treatment with the dopamine agonist cabergoline in patients unsuccessfully treated by surgery. Journal of Clinical Endocrinology and Metabolism 200994 223-230. (doi:10.1210/jc.2008-1533)

8 Vilar L, Naves LA, Azevedo MF, Arruda MJ, Arahata CM, Moura E Silva L, Agra R, Pontes L, Montenegro L, Albuquerque JL et al. Effectiveness of cabergoline in monotherapy and combined with ketoconazole in the management of Cushing's disease. Pituitary 2010 13 123-129. (doi:10.1007/s11102-009-0209-8)

9 Barbot M, Albiger N, Ceccato F, Zilio M, Frigo AC, Denaro L, Mantero F \& Scaroni C. Combination therapy for Cushing's disease: 
effectiveness of two schedules of treatment: should we start with cabergoline or ketoconazole? Pituitary 201417 109-117. (doi:10.1007/ s11102-013-0475-3)

10 Burman P, Edén-Engström B, Ekman B, Karlsson FA, Schwarcz E \& Wahlberg J. Limited value of cabergoline in Cushing's disease: a prospective study of a 6-week treatment in 20 patients. European Journal of Endocrinology $2016 \mathbf{1 7 4}$ 17-24. (doi:10.1530/EJE-15-0807)

11 Vidal J. Updated review on the benefits of weight loss. International Journal of Obesity and Related Metabolic Disorders 200226 S25-S28. (doi:10.1038/sj.ijo.0802215)

12 Chiodini I, Morelli V, Salcuni AS, Eller-Vainicher C, Torlontano M, Coletti F, Iorio L, Cuttitta A, Ambrosio A, Vicentini L et al. Beneficial metabolic effects of prompt surgical treatment in patients with an adrenal incidentaloma causing biochemical hypercortisolism. Journal of Clinical Endocrinology and Metabolism 201095 2736-2745. (doi:10.1210/jc.2009-2387)

13 Mancia G, De Backer G, Dominiczak A, Cifkova R, Fagard R, Germano G, Grassi G, Heagerty AM, Kjeldsen SE, Laurent S et al. 2007 ESH-ESC practice guidelines for the management of arterial hypertension: ESH-ESC task force on the management of arterial hypertension. Journal of Hypertension 200725 1751-1762. (doi:10.1097/HJH.0b013e3282f0580f)

14 Wertheimer AI. The defined daily dose system (DDD) for drug utilization review. Hospital Pharmacy 198621 233-234, 239-241, 258.

15 Merlo J, Wessling A \& Melander A. Comparison of dose standard units for drug utilisation studies. European Journal of Clinical Pharmacology 199650 27-30. (doi:10.1007/s002280050064)

16 Bevan JS, Webster J, Burke CW \& Scanlon MF. Dopamine agonists and pituitary tumor shrinkage. Endocrinology. Reviews 199213 220-240. (doi:10.1210/edrv-13-2-220)

17 T'Sjoen G, Defeyter I, Van De Saffele J, Rubens R \& Vandeweghe M. Macroprolactinoma associated with Cushing's disease, successfully treated with cabergoline. Journal of Endocrinological Investigation 2002 25 172-175. (doi:10.1007/bf03343983)

18 Petrossians P, Ronci N, ValdésSocin H, Kalife A, Stevenaert A, Bloch B, Tabarin A \& Beckers A. ACTH silent adenoma shrinking under cabergoline. European Journal of Endocrinology 2001144 51-57. (doi:10.1530/eje.0.1440051)

19 Manavela MP, Danilowicz K \& Bruno OD. Macrocorticotropinoma shrinkage and control of hypercortisolism under long-term cabergoline therapy: case report. Pituitary 201215 (Supplement 1) 33-36. (doi:10.1007/s11102-011-0309-0)

20 Papanicolaou DA, Yanovski JA, Cutler GB, Chrousos GP \& Nieman LK. A single midnight serum cortisol measurement distinguishes Cushing's syndrome from pseudo-Cushing states. Journal of Clinical Endocrinology and Metabolism 199883 1163-1167. (doi:10.1210/jc.83.4.1163)

21 Lila AR, Gopal RA, Acharya SV, George J, Sarathi V, Bandgar T, Menon PS \& Shah NS. Efficacy of cabergoline in uncured (persistent or recurrent) Cushing disease after pituitary surgical treatment with or without radiotherapy. Endocrine Practice 201016 968-976. (doi:10.4158/EP10031.OR)

22 Feelders RA, De Bruin C, Pereira AM, Romijn JA, Netea-Maier RT, Hermus AR, Zelissen PM, Van Heerebeek R, de Jong FH, Van der Lely A-J et al. Pasireotide alone or with cabergoline and ketoconazole in Cushing's disease. New England Journal of Medicine 2010362 1846-1848. (doi:10.1056/NEJMc1000094)

23 Castinetti F, Guignat L, Giraud P, Muller M, Kamenicky P, Drui D, Caron P, Luca F, Donadille B, Vantyghem MC et al. Ketoconazole in Cushing's disease: is it worth a try? Journal of Clinical Endocrinology and Metabolism 201499 1623-1630. (doi:10.1210/jc.2013-3628)

24 Daniel E, Aylwin S, Mustafa O, Ball S, Munir A, Boelaert K, Chortis V, Cuthbertson DJ, Daousi C, Rajeev SP et al. Effectiveness of metyrapone in treating Cushing's syndrome: a retrospective multicenter study in 195 patients. Journal of Clinical Endocrinology and Metabolism 2015100 4146-4154. (doi:10.1210/jc.2015-2616)

25 Howlett TA, Willis D, Walker G, Wass JAH, Trainer PJ \& UK Acromegaly Register Study Group (UKAR-3). Control of growth hormone and IGF1 in patients with acromegaly in the UK: responses to medical treatment with somatostatin analogues and dopamine agonists. Clinical Endocrinology 201379 689-699. (doi:10.1210/jc.83.4.1163)

26 Trainer PJ. ACROSTUDY: the first 5 years. European Journal of Endocrinology 2009161 S19-S24. (doi:10.1530/EJE-09-0322)

27 Sandret L, Maison P \& Chanson P. Place of cabergoline in acromegaly: a meta-analysis. Journal of Clinical Endocrinology and Metabolism 2011 96 1327-1335. (doi:10.1210/jc.2010-2443)

28 Higham CE, Atkinson AB, Aylwin S, Bidlingmaier M, Drake WM, Lewis A, Martin NM, Moyes V, Newell-Price J \& Trainer PJ. Effective combination treatment with cabergoline and low-dose pegvisomant in active acromegaly: a prospective clinical trial. Journal of Clinical Endocrinology and Metabolism 201297 1187-1193. (doi:10.1210/jc.2011-2603)

29 Colao A, Petersenn S, Newell-Price J, Findling JW, Gu F, Maldonado M, Schoenherr U, Mills D, Salgado LR, Biller BMK et al. A 12-month phase 3 study of pasireotide in Cushing's disease. New England Journal of Medicine 2012366 914-924. (doi:10.1056/NEJMoa1105743)

30 Findling JW \& Raff H. Screening and diagnosis of Cushing's syndrome. Endocrinology and Metabolism Clinics of North America 2005 34 385-402. (doi:10.1016/j.ecl.2005.02.001)

31 Tritos NA, Biller BMK \& Swearingen B. Management of Cushing disease. Nature Reviews Endocrinology 20117 279-289. (doi:10.1038/ nrendo.2011.12)

32 Boscaro M, Barzon L, Fallo F \& Sonino N. Cushing's syndrome. Lancet 2001357 783-791. (doi:10.1016/S0140-6736(00)04172-6)

33 Kumari M, Shipley M, Stafford M \& Kivimaki M. Association of diurnal patterns in salivary cortisol with all-cause and cardiovascular mortality: findings from the Whitehall II study. Journal of Clinical Endocrinology and Metabolism 201196 1478-1485. (doi:10.1210/jc.2010-2137)

34 Terzolo M, Bovio S, Pia A, Conton PA, Reimondo G, Dall'Asta C, Bemporad D, Angeli A, Opocher G, Mannelli M et al. Midnight serum cortisol as a marker of increased cardiovascular risk in patients with a clinically inapparent adrenal adenoma. European Journal of Endocrinology 2005153 307-315. (doi:10.1530/eje.1.01959)

35 Murphy MB. Dopamine: a role in the pathogenesis and treatment of hypertension. Journal of Human Hypertension 200014 S47-S50. (doi:10.1038/sj.jhh.1000987)

36 Bertagna X, Raux-Demay MC, Guilhaume B, Girard F \& Luton JP. Cushing's disease. In The Pituitary, edn 2, pp 478-545. Eds S Melmed. Los Angeles, CA, USA: Blackwell Science, 1995.

37 Petersenn S, Newell-Price J, Findling JW, Gu F, Maldonado M, Sen K, Salgado LR, Colao A, Biller BMK \& Pasireotide B2305 study group. High variability in baseline urinary free cortisol values in patients with Cushing's disease. Clinical Endocrinology 201480 261-269. (doi:10.1111/cen.12259)

38 Pivonello R, De Leo M, Cozzolino A \& Colao A. The treatment of Cushing's disease. Endocrine Reviews 201536 385-486. (doi:10.1210/ er.2013-1048)

39 Corcuff J-B, Young J, Masquefa-Giraud P, Chanson P, Baudin E \& Tabarin A. Rapid control of severe neoplastic hypercortisolism with metyrapone and ketoconazole. European Journal of Endocrinology 2015 172 473-481. (doi:10.1530/EJE-14-0913)

40 Clayton RN, Jones PW, Reulen RC, Stewart PM, Hassan-Smith ZK, Ntali G, Karavitaki N, Dekkers OM, Pereira AM, Bolland M et al. Mortality in patients with Cushing's disease more than 10 years after remission: a multicentre, multinational, retrospective cohort study. Lancet Diabetes Endocrinology 20164 569-576. (doi:10.1016/S2213-8587(16)30005-5) 